\title{
La economía y la sociedad del conocimiento. Hacia la tercera revolución: la información
}

\section{RESUMEN}

Conocimiento es el conjunto organizado de datos e información con un fin específico que puede ser la develación de la verdad o la resolución de un problema. Dentro de la perspectiva Baconiana, la economía es la actividad humana que emplea recursos escasos para generar y distribuir riqueza. El desarrollo es un proceso de crecimiento económico y mayor bienestar social. El proceso actual se caracteriza por la innovación tecnológica, el comercio mundial de bienes y servicios y la gestión e intercambio de conocimiento básico y aplicado entre comunidades académicas y empresariales. Este fenómeno se denomina Sociedad de la Información y el Conocimiento (SIC), surge con el boom convergente de sectores de alta tecnología y una estructura de redes de información global que permite la consolidación de cadenas productivas y capacidad competitiva con efectos mundiales.

Palabras clave: Conocimiento, Sociedad del Conocimiento, Economía en Red, Estrategia.

The ECONNOMY AND THE KNOWLEDGE SOCIETY. TOWARDS THE THIRD REVOLUTION: INFORMATION

\section{ABSTRACT}

Knowledge is a body of data and information for a specific purpose may be the unveiling of the truth or solving a problem. Within the Baconian perspective, the economy is human activity that uses scarce resources to generate and distribute wealth. Development is a process of economic growth and greater social welfare. The current process is characterized by technological innovation, global trade of goods and services, and management and exchange of basic and applied knowledge among academic and business communities.

This phenomenon is called the Information and Knowledge Society (IKS) that comes with boom of convergence of high technology sectors and structure of global information networks that enables the consolidation of productive chains, raising competitiveness with global impact.

KEYwords: Knowledge, Knowledge Society, Network Economics, Strategy.

\section{INTRODUCCIÓN}

Bajo el enfoque sistémico, la Sociedad de la Información y el Conocimiento (SIC) se considera un arreglo de componentes: estructuras, procesos, personas y momentos, orientados a la gestión y difusión del conocimiento y que se enlazan e interactúan a través de flujos de datos, información y conocimiento que circulan por las carreteras de la información (Acevedo, 2003).

El componente estructural se refiere al ordenamiento y sistematización de los diferentes tipos de conocimiento, a cargo de las comunidades académicas. El componente de proceso comprende el trabajo de conceptualización, organización acumulación y gestión de las informaciones que permiten la generación del conocimiento. El componente personas se refiere a cada comunidad académica que se encarga de la actividad de gestionar un sector de conocimiento especializado. El componente de momento se refiere a las fuerzas que han permitido este cambio exponencial en el volumen y manejo de datos, informaciones y conocimiento.

Los flujos que relacionan a los componentes son de dos tipos. Los flujos físicos se transforman en el proceso o brindan energía, se presentan en tres categorías: materia, datos y energía. Los datos se archivan en medios físicos de información, sea papel, audiovisual, magnético o electrónico (bytes) que circulan a través de las redes. Los flujos no físicos son de tres categorías: información, conocimiento y contenidos. La información comprende datos procesados con instrucciones (dato + significado). El conocimiento es el valor del saber, saber hacer, descubrir y crear. Los contenidos son los mensajes y el intercambio de símbolos, creencias, visiones, conductas.

\section{EL CONCEPTO DE LA SOCIEDAD DEL CONOCIMIENTO}

La Sociedad de la Información y el Conocimiento es la fase superior del desarrollo económico y social que se deriva del acelerado cambio tecnológico, afianzado con la aparición de nuevos

1 Magíster en Administración, Ingeniero Industrial, Economista. Profesor en la Facultad de Ingeniería Industrial, Departamento de Producción y Gestión Industrial de la UNMSM. E-mail: aacevedo@speedy.com.pe

2 Magíster en Dirección de Empresas, Ingeniera Industrial, estudios de Derecho. Profesora en la Facultad de Ingeniería de Sistemas e Informática de la UNMSM. E-mail: klinares@speedy.com.pe

3 Magíster en Administración, Ingeniero Industrial, Decano FII-UNMSM. E-mail: orestescachay@ yahoo.es 


\title{
GRÁFICO 1. CONCEPTOS EN LA SOCIEDAD DE LA INFORMACIÓN Y EL CONOCIMIENTO (SIC)
}

\author{
Sociedad de la información y el conocimiento $=$ \\ Soc. de información + Gestión de conocimiento + Proceso de desarrollo + Calidad de vida
}

- Soc. de información = redes complejas + flujo de información + e-servicios (ciudadano-empresa)

- Proceso de desarrollo = crecimiento económico + bienestar social

- Calidad de vida $=$ cond familia + cond $w^{\circ}+$ cond sociales + cond entorno

\section{Gestión del conocimiento $=$} Tipos conocimiento + Admin. capital intelectual + Comunicación + (Aprendizaje + Uso)

- Tipos de conocimiento $=(\text { tácito, explícito })^{*}($ básico, tecnológico, innovaciones, práctico $)$

- Admin. capital intelectual = generación, registro, recuperación, distribución

- Comunicación = información + acceso

- Aprendizaje $=$ contenido + estilo de aprendizaje + perfil de talento

- Uso = saber verdadero + bien verdadero

Elaboración propia.

sectores económicos de hardware y software y la convergencia tecnológica de las redes de telecomunicación con Internet, computación, conformando un gran sector denominado de las tecnologías de información y comunicación (TIC), complementariamente ha surgido la corriente académica de la gestión del conocimiento que aprovecha la tecnología para la administración y difusión del capital intelectual para crear valor en las empresas.

\section{Conocimiento y sociedad del conocimiento}

Conocimiento es saber. Es la idea o noción de un objeto como resultado del proceso cognitivo (Quintás, 2002), es la serie de transformaciones en el tratamiento personal de la información para obtener entendimiento y representaciones mentales de las cosas.

Sobre el conocimiento se han elaborado diversos modelos. El conocimiento puede ser demostrable y metafísico (Aristóteles), el primero se refiere a los fenómenos de la realidad que pueden ser explicados por las leyes físicas de la naturaleza, el segundo se refiere a las cosas que están completamente separadas de la materia, por ende, no son verificables. Desde la perspectiva de gestión, el conocimiento es de dos tipos tácito y explícito, el primero es individual y está en la persona, el segundo está en la organización, es acumulable y administrable (Nonaka y Takeuchi, 1999).

Dentro de las sociedades humanas, se intenta alcanzar el desarrollo, el cual se define como un proceso de crecimiento económico y elevación del bienestar social. El proceso de desarrollo vigente desde fines del siglo XX, se caracteriza por el boom de la innovación tecnológica que se compor- ta bajo modelos biológicos y el intercambio mundial de bienes y servicios, sin límites de distancia y tiempo, que ha llevado a cambios de paradigmas $y$ creencias, nuevas formas organizativas $y$, lo que es más importante, la gestión e intercambio global de conocimiento básico y aplicado, que fluye entre diferentes comunidades académicas, científicas, de investigación y empresariales, a través de redes de comunicación interconectadas (Le Monde Diplomatique, 2002). Este fenómeno inédito, que genera nuevos conceptos y modelos, se denomina Sociedad de la Información y el Conocimiento (Gráfico 1).

El modelo de la SIC ha permitido que la información y el conocimiento se tornen accesibles, sin límites. Los diversos tipos de conocimiento se han visto modificados en todas las sociedades urbanas. En la SIC, la innovación se orienta al pragmatismo, donde la creación tecnológica y las patentes son la forma tangible y deseable del valor del conocimiento.

\section{Definición de la SIC}

La Sociedad de la Información y el Conocimiento es la fase vigente del desarrollo económico y social, se caracteriza por la capacidad de sus miembros (ciudadanos, empresas y gobiernos) para gestionar el conocimiento derivado del acceso instantáneo a la información pertinente, desde cualquier lugar y en cualquier forma. Su finalidad es ampliar los beneficios del conocimiento a todas las comunidades, dentro de un proceso de cambio acelerado, mundial, global, irreversible y participativo, que ha de permitir que las regiones de menor desarrollo se encuentren posibilitadas de equipararse a las más desarrolladas. 


\section{GRÁFICO 2. EL MODELO SISTÉMICO DE LA SOCIEDAD DE LA INFORMACIÓN Y EL CONOCIMIENTO}

\begin{tabular}{|c|c|c|}
\hline $\begin{array}{c}\text { Situación previa } 1 \\
\text { Sociedad postindustrial } \\
\text { Foco en procesos globales } \\
\text { de intercambio de servicios y } \\
\text { bienes. } \\
\text { Énfasis en la generación de } \\
\text { datos e información basado en } \\
\text { infraestructura de comunicación, } \\
\text { Internet y PCs }\end{array}$ & $\begin{array}{c}\text { SIC } \\
\text { La SIC es la fase del desarrollo, donde se } \\
\text { obtiene conocimiento e información a través } \\
\text { del acceso al ciberespacio, en cualquier forma, } \\
\text { en cualquier lugar, en cualquier momento, } \\
\text { a fin de crear competencias sectoriales, } \\
\text { organizacionales y personales, mediante } \\
\text { procesos de cambio, adaptación y aprendizaje } \\
\text { permanente. }\end{array}$ & $\begin{array}{l}\text { Situación posterior } 2 \\
\text { Sociedad del conocimiento } \\
\text { Foco en el cambio y } \\
\text { aprendizaje para crear } \\
\text { competencias a partir de la } \\
\text { gestión del conocimiento y } \\
\text { el capital intelectual en las } \\
\text { organizaciones. }\end{array}$ \\
\hline
\end{tabular}

FUENTE: Acevedo, Linares. El desarrollo tecnológico de las comunicaciones. Rev.AHCIET, 2006.

En su definición rigurosa, la SIC tiene como objetivo la eliminación de la brecha digital (Hernani y Martínez, 2002) a través de la cooperación de las comunidades científicas que se interrelacionan entre sí y con los actores empresariales del sector TIC para plantear horizontes comunes, experimentar e intercambiar conocimientos y experiencias, la finalidad es la promoción del desarrollo y la integración de los países, mediante la creación de los medios para satisfacer necesidades de conocimiento e información, diseñar y construir aplicaciones innovadoras y coordinar el marco de desarrollo de la SIC.

La definición amplia de la SIC señala que la sociedad de la información se torna en la sociedad del conocimiento, a partir del crecimiento de la comunicación y la profundización de los mecanismos de cambio y aprendizaje organizacional, con el fin de adquirir capacidades y competencias que permitan adaptarse y crecer en los nuevos entornos de turbulencia y caos. La SIC es una sociedad de la comunicación y el aprendizaje (Acevedo y Linares, 2006). Ver el Gráfico 2.

\section{El camino hacia la Sociedad del Conocimiento}

El desarrollo es un proceso permanente de cambio acumulativo, mediante ciclos repetitivos en una espiral de mejora. En este proceso, el eje de la mejora depende de los valores y requerimientos prevalecientes de la sociedad. El eje va cambiando en función a nuevas prioridades y circunstancias, sin dejar de lado lo ya aprendido, sistematizado y acumulado, lo que lleva a niveles superiores en la resolución de los problemas complejos de la sociedad (Blair \& Whitston, 1973).). Ver el Gráfico 3.

El eje humano. Se considera que la civilización se inicia alrededor de 5000 a.C., con la aparición de las primeras ciudades y las artes técnicas, se da la primera revolución industrial derivada del descubrimiento de la agricultura y el sedentarismo. En esta etapa, el conocimiento se concentra en las personas (genealogías bíblicas durante cinco milenios), por el año 2000 a.C., se deja evidencia escrita de este conocimiento primigenio mediante rudimentarias tablas de arcilla y pergaminos.

El eje estructural. La civilización occidental se inicia con los sumerios y babilonios y toma su forma actual en la Grecia Antigua, con la primera acumulación sistematizada de conocimiento (años 300 a.C.-100 a.C.) a través de la Academia y luego con el Peripato que cuidó la edición de los escritos acroamáticos de Aristóteles, base de la Biblioteca de Alejandría, que en su esplendor contenía los escritos con todo el conocimiento desarrollado en el mundo antiguo. El conocimiento de la antigüedad llega a Europa a través del intercambio cultural de las Cruzadas y la sostenida labor de los Benedictinos que preservan gran parte del saber humano en la abadía de Montecasino (Pazos, Rodríguez, Rodríguez-Patón, Suárez, 2007).

El eje del proceso. En el siglo XIX, se inicia la consolidación del modelo capitalista y surge la segunda revolución industrial, caracterizada por la explosión de la producción y consumo masivo de productos, que satisfacen necesidades de una masa poblacional creciente. En la Edad Moderna se da la aparición de las universidades, la difusión del pensamiento filosófico y científico de los griegos, musulmanes y orientales. Luego viene la denominada etapa postindustrial, donde se van reduciendo las barreras de intercambio comercial y la producción de los servicios asume importancia creciente. 


\section{GRÁFICO 3. EJES FOCALES EN EL CAMINO HACIA LA SOCIEDAD DEL CONOCIMIENTO}

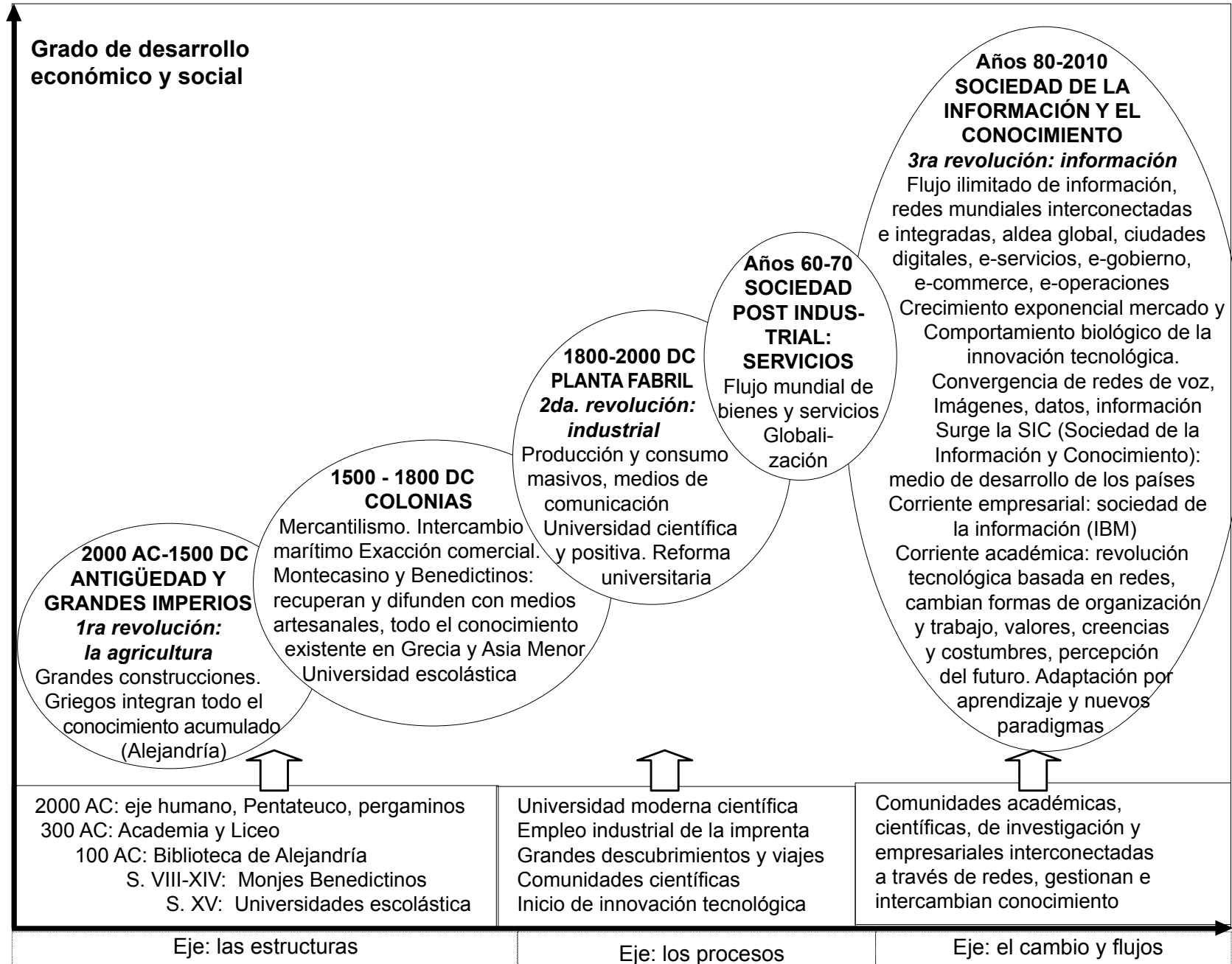

Elaboración propia.

El eje del cambio. Los nuevos pilares del desarrollo son el intercambio de datos e información basado en redes mundiales de telecomunicación integradas con tecnologías de información, computación y multimedia. Este flujo ilimitado de datos e información trae nuevos comportamientos organizacionales e individuales, nuevas reglas de mercado y nuevas estrategias organizacionales. Por los cambios drásticos se define que este proceso es la tercera revolución industrial: la revolución del conocimiento.

\section{LA ECONOMÍA EN LA SOCIEDAD DE LA INFORMACIÓN Y EL CONOCIMIENTO}

\section{El marco conceptual de la nueva economía}

Los sectores TIC y la red de telecomunicaciones sustentan las reglas de juego de la nueva economía, también denominada economía en red. A partir de los años ochenta del siglo $X X$, surgieron fuerzas que han transformado a las organizaciones produc- tivas y sociales. Las fuerzas son: a) Aceleración del cambio tecnológico. b) Aceleración del conocimiento. c) Auge de la competencia. d) Fin de los sistemas jerárquicos tradicionales.

Las redes de conocimiento fluyen sobre las redes de información, éstas se sustentan en un esqueleto de medios de interconexión física denominado backbone, el cual es una autopista virtual por donde circulan los datos y la información en sus diferentes formas analógicas y digitales (bytes, datos, voz, imágenes), permitiendo la gestión del conocimiento en las organizaciones.

Las empresas emplean las tecnologías de información y diseñan modelos de negocio que enfatizan la creación de valor virtual, recomponen la operación de sus sistemas internos y desarrollan ventajas competitivas a partir de su capital intelectual. Las organizaciones que gestionan el conocimiento de sus empleados y lo convierte en capital explícito, 


\section{GRÁFICO 4. LA ECONOMÍA TRADICIONAL Y LA NUEVA ECONOMÍA}

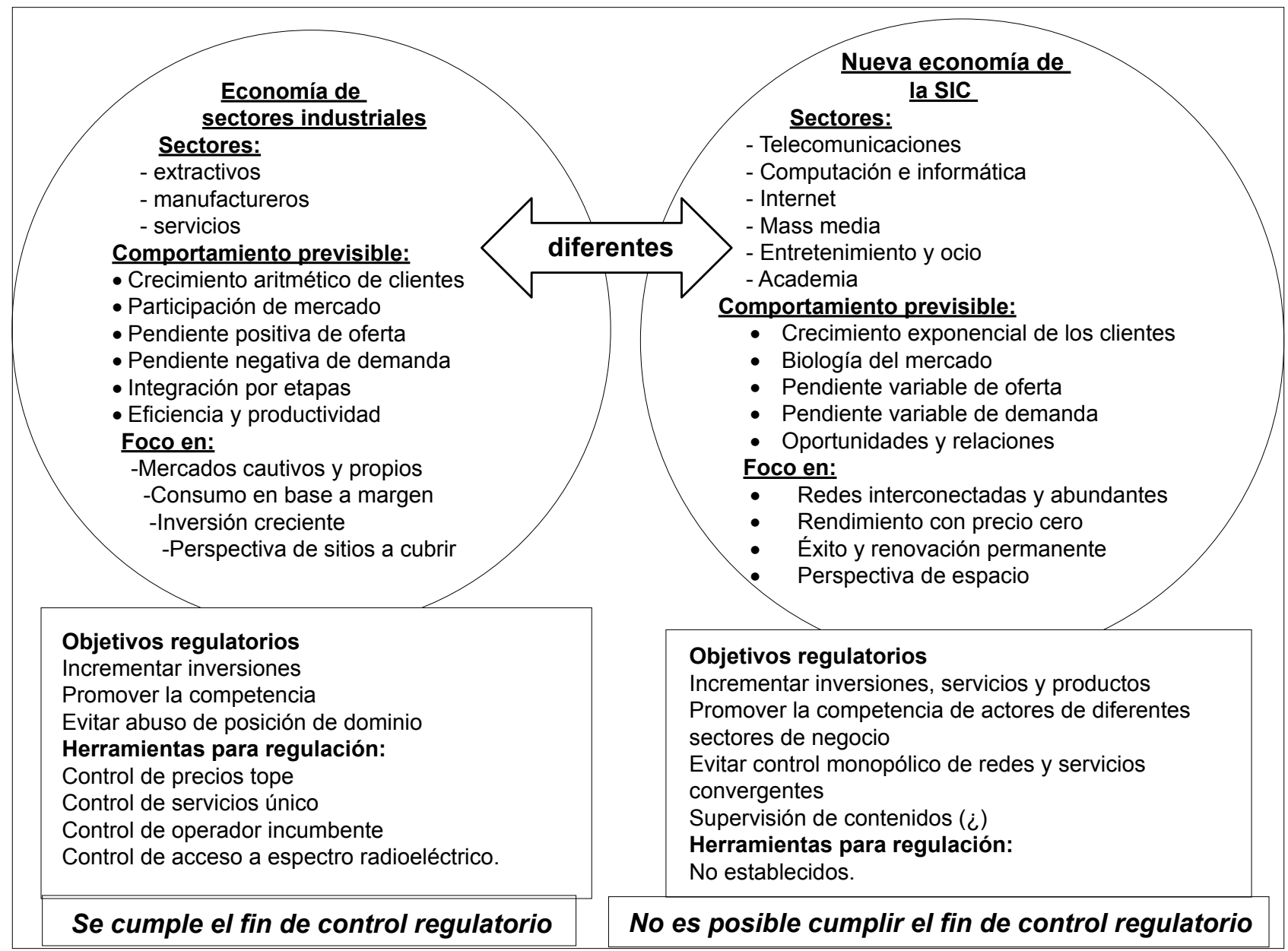

FUENTE: Linares, Carolina. El reto regulatorio en el contexto de la SIC.

son las empresas del futuro, denominadas empresas cognitivas o del conocimiento. En la economía de la Sociedad de la Información y el Conocimiento, el reto es generar valor a través del funcionamiento de la economía de las redes de comunicación.

Este nuevo paradigma económico se comporta como un modelo de crecimiento biológico, opuesto al modelo de crecimiento lineal vigente (Gráfico 4). La economía tradicional y la nueva economía subsisten paralelamente, se entrecruzan pero no se mezclan. El primero sigue siendo válido en los sectores industriales primarios y de transformación, el segundo va cubriendo paulatinamente a todos los sectores de servicios y cambia la operatividad y la organización de todas las industrias.

\section{Los atributos de la economía en red}

La economía que surge con la revolución de la información y la comunicación posee tres características:

1. Es global, interconectada e intangible.
2. Se basa en la tecnología digital y los medios de comunicación.

3. Soporta flujos crecientes de datos, información y conocimiento.

En esta nueva economía se manejan dos conceptos clave:

1. La comunicación de las partes o nodos, que conforman la red interconectada.

2. La computación para procesar los datos e información.

Los atributos relevantes de la economía en red son:

1. Es una red de nodos, con relaciones e interconexiones, en otras palabras es un sistema con muchos puntos conectados:

- Se define que se ha de plantar un chip (con información) en cada cosa que se fabrique.

- Todo lo que se fabrique ha de estar conectado a la red.

- Diseño de potencia tonta, que es la capacidad de unir cosas tontas para obtener algo muy listo. 
La economía y la sociedad del conocimiento.

Hacia la tercera revolución: la información

2. Cada punto de nodo es un emisor y un receptor a la vez:

- Todos los objetos conversan entre sí.

- La nueva matriz de información fluye de y hacia todas partes.

- La información existe en todo el mundo.

\section{La ruptura de las reglas de mercado}

Todas las organizaciones deberán aprehender las nuevas reglas del juego económico y aprender a jugar con estas reglas de ruptura. Como ejemplo se presenta el caso del equilibrio de mercado en la economía en red (Gráfico 5).

\section{GRÁFICO 5. EQUILIBRIO DE MERCADO EN LA ECONOMÍA EN RED}

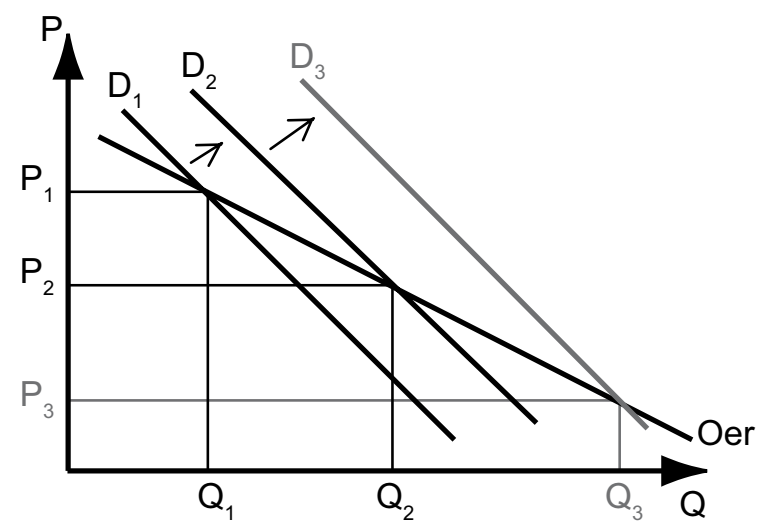

Elaboración propia.

En la microeconomía clásica, el equilibrio de mercado se alcanza cuando la curva de oferta se interseca con la curva de demanda, esto significa que a un determinado precio $P_{1}$, la cantidad demandada es igual a la cantidad ofertada $Q_{1}$. Ambas curvas tienen pendiente diferente, si el precio sube la cantidad demandada baja y la cantidad ofertada sube, si el precio baja la cantidad demandada sube y cantidad ofertada baja (Parkin, 1995).

Pero el caso de la economía en red es diferente. Debido al acelerado cambio tecnológico, la oferta crece permanentemente y los precios bajan sostenidamente, o sea, la oferta se eleva con la reducción de precio. El cliente que compra (por ejemplo) su primer chip pagará el precio $P_{1}$, la cantidad $Q_{1}$ representa el número de clientes que adquieren el producto. Unos meses después el precio del chip se reduce a $\mathrm{P}_{2}$ y la oferta se eleva, el ofertante (empresa fabricante de chip) busca la manera de aumentar la demanda, para lo cual regala el producto para incentivar su uso, esto permite el ingreso de un segmento de clientes de menor capacidad adquisitiva $\left(Q_{2}-Q_{1}\right)$ en la realidad, la curva de demanda se desplaza de $D_{1}$ hacia $D_{2}$.

El precio sigue bajando a $P_{3}$, la oferta se sigue reduciendo dentro de su línea de oferta $\mathrm{O}_{\mathrm{er}}$ y la demanda se sigue desplazando a $D_{3}$. De esta manera, el cliente percibe que el precio de los productos tecnológicos se reducen sostenidamente y la oferta se eleva en calidad, capacidad de procesamiento y prestaciones adicionales. Si la tendencia y la meta es llegar al costo cero por el uso del servicio, se deberán tener reglas y estrategias (aún no diseñadas) para mantener una oferta superavitaria, dentro de modelos de negocio rentables.

Las empresas están aprendiendo, en la práctica, cómo se diseñan y se aplican los conceptos económicos dentro de los nuevos modelos empresariales de organizaciones en red, fábrica virtual, valor virtual, operación global.

\section{Las dimensiones y niveles de resolución de la nueva economía}

La economía de la SIC posee cuatro dimensiones, las que se diseñan en el nivel 1 conceptual, se dirigen en el nivel 2 estratégico y se operacionalizan en el nivel 3 de las organizaciones.

La primera dimensión comprende el sistema técnico-estructural. En el aspecto estructural se presenta una situación nunca antes existente: el tamaño y alcance de la inversión en redes de comunicación interconectadas es de tal magnitud que, por primera vez, todo el planeta está cableado, con lo que se conforma un esqueleto de comunicación que ha eliminado las barreras físicas del tiempo y el espacio.

En la dimensión de los sistemas productivos se ha conformado un solo mercado. El cableado ha generado un mercado mundial y se han creado nuevos canales comerciales basados en la tecnología digital, lo que ha cambiado el funcionamiento de los sistemas empresariales. Esto determina que se acelere la velocidad de las actividades, los procesos financieros y productivos devienen en instantáneos y virtuales, aumenta la calidad de vida y los trabajadores en servicios tienden a crecer.

En la dimensión de los sistemas sociales o humanos, se plantea que, hoy, existe el mercado más grande, de mayor capacidad adquisitiva y de mayor preparación y conocimiento de todos los tiempos, donde la segmentación llega a niveles de personalización e individualización de los deseos y requeri- 
mientos de los clientes. Se acerca un cambio trascendente en la calidad de vida, aunque las modas sociales postmodernistas pueden llevar a la aparición de mecanismos de degradación social, segregación o explotación más sutiles e invisibles, por lo tanto, más peligrosos.

En la dimensión de los sistemas de cambio, se observa una capacidad creciente y autogenerativa de innovación tecnológica cuyo comportamiento exponencial de creación de nuevo conocimiento se asemeja al modelo reproductivo de los organismos biológicos. La aceleración tecnológica resulta en un enorme despliegue de nuevos productos, nuevos servicios y nuevas máquinas que cambian y mejoran la productividad y la calidad de vida.

El cambio tecnológico ha creado nuevos territorios de producción económica: sectores y negocios inéditos: computación (procesadores, nanotecnología, hardware), informática (programación, software, manejo de datos e información), interfaces hombre-máquina, Internet (ciberespacio, realidad virtual), que se integran con otros sectores como telecomunicaciones, comunicación masiva, entretenimiento, para conformar la sociedad actual, supercomunicada, con culturas, valores, creencias y conductas que se difunden, se perciben y se integran globalmente (Christensen, 1999).

\section{LA GESTIÓN EMPRESARIAL EN LA ECONOMÍA DE LA SIC}

La economía en red está cambiando a las organizaciones de negocio y las organizaciones sociales (Magretta, 2001). Las empresas del sector TIC conforman un cluster tecnológico de alcance mundial, que se orienta a la convergencia con los sectores de comunicación pública masiva, transmisión de voz, datos e imágenes y el sector de entretenimiento.

Los elementos de la gestión empresarial que se están replanteando y redefiniendo, se agrupan en los tres niveles de resolución de las organizaciones y se sustentan en la praxis de los nuevos sectores, creados y consolidados hace no más de tres décadas.

A nivel conceptual, se consideran los elementos para la creación de paradigmas del sector, bajo una perspectiva sistémica y de modelamiento conceptual:

1. Las fuerzas que orientan el futuro y dinamizan el cambio de la SIC.

2. Las reglas de juego de la economía interconectada.
3. El modelo de negocio sostenible y la killer application.

4. La creación de valor en la cadena de valor.

A nivel estratégico, se consideran los elementos para delinear la visión y futuro de las organizaciones, bajo la perspectiva de decisiones y resolución de problemas:

1. Las estrategias para la economía interconectada de la SIC.

2. La administración de los sistemas empresariales en las empresas.

3. Herramientas de la arquitectura organizativa de las empresas.

4. La toma de decisiones en la economía en red.

A nivel gerencial, se consideran los elementos para la productividad, eficacia y resultados, bajo la perspectiva de asignación de recursos y productividad:

1. Criterios a operacionalizar en la economía en red.

2. La gestión de la innovación tecnológica de ruptura.

3. El posicionamiento y segmentación de las nuevas organizaciones.

4. La gestión del cliente en las nuevas organizaciones.

5. Tácticas de mercadeo empleando e-marketing.

Las fuerzas que orientan el futuro de la SIC y dinamizan el cambio.

Las fuerzas dinámicas que determinarán el futuro de las organizaciones que operan competitivamente en el sector de la información y el conocimiento (Kelly, 1997), son cinco:

1.- Crecimiento tecnológico exponencial. Es un modelo análogo al crecimiento biológico de los organismos vivos. Este crecimiento supera a los modelos de crecimiento mecánico o lineal, típico de la planta fabril de la segunda revolución industrial.

2.- Rendimientos crecientes. Empíricamente se da la ley del rendimiento creciente o de los bucles de retroalimentación positiva. Este modelo replica el efecto bola de nieve del éxito que atrae el éxito: si ahora atrae un nivel de inversiones, en el futuro atraerá aún más inversiones.

3.- Valor compuesto. Los cambios y resultados no crecen por multiplicación sino por exponenciación, en forma semejante al modelo del interés compuesto. El ejemplo resaltante es el tamañocapacidad de los procesadores, a medida que 
se reduce el tamaño aumenta la capacidad de almacenaje.

4.- Efecto fax. A mayor cantidad de usuarios, mayor será el valor de la tecnología. Como ejemplo, el primer teléfono no valía nada porque no se comunicaba con nadie, el segundo teléfono asignaba valor a ambos teléfonos, semejante es el caso del correo electrónico, a mayor cantidad de usuarios, más valiosa será la red, ya que la ubicuidad aumenta su valor y utilidad.

El crecimiento de mercado se mide, no por el incremento sobre la base anterior de clientes sino por la nueva base elevada al cuadrado, de esta manera, el volumen potencial de negocio derivado de las combinaciones de transacciones posibles se eleva a magnitudes superiores a las de la medición de proporciones.

5.- Creación de riqueza a partir de precio cero. El objetivo crítico de alcanzar la masa crítica de mercado, determina que se diseñen estrategias de precio cero, como el regalo del producto o servicio, donde el cliente no paga por el acceso sino por el servicio. El ejemplo clave es el regalo de PCs para usar Internet. Dentro de la concepción de estrategia competitiva, el primero que regala el producto, genera posicionamiento e identidad de marca y de empresa.

\section{Reglas de juego y estrategias de la economía interconectada}

La economía en red origina un nuevo marco conceptual que cambia drásticamente la percepción del funcionamiento sectorial y renueva los paradigmas de la economía. A fines de los años noventa, basado en las propuestas de ruptura de la revista Wired, Kelly difunde las reglas que han de regir la economía de redes interconectadas del nuevo milenio (Kelly, 1999). Las diez reglas empíricas propuestas indican la dirección que va tomando el entorno económico y el lugar de los nuevos actores de la sociedad del conocimiento.

Estas reglas para la economía interconectada requieren el diseño de estrategias radicales y aún en proceso de diseño, con la mira visionaria de ir creando, paso a paso, el edificio de la economía del presente siglo, e ir fortaleciendo, desde sus cimientos, la teoría de la nueva economía, que va surgiendo, a la par de la nueva praxis de redes interconectadas, productos y servicios convergentes y nuevo sectores con nuevos modelos de negocio.

El Cuadro 1 muestra las reglas empíricas en propuesta y aún en desarrollo.

\section{CUADRO 1. REGLAS Y DISEÑO DE LAS ESTRATEGIAS DE LA NUEVA ECONOMÍA}

\begin{tabular}{|c|c|c|}
\hline Reglas & Estrategias & Criterios a operacionalizar \\
\hline $\begin{array}{l}\text { 1.- Aprovechar la estructura } \\
\text { de colmena, ser parte } \\
\text { de la red. }\end{array}$ & $\begin{array}{l}\text { 1. Aprovechar el poder de la descentralización. } \\
\text { 2. Usar la tecnología, siempre presente e invisible. } \\
\text { 3. Conectar todos los elementos. } \\
\text { 4. Emplear conocimiento. Captar el tácito, } \\
\text { distribuir el explícito. } \\
\text { 5. Hacer que todo funcione en tiempo real. } \\
\text { 6. Hacer siempre más, en todas las } \\
\text { circunstancias. }\end{array}$ & $\begin{array}{l}\text { - El futuro es en red. } \\
\text { - La dinámica social y económica seguirá la dinámica de } \\
\text { las redes. } \\
\text { - Todo está conectado. } \\
\text { - Todas las cosas que transmiten información están vivas. } \\
\text { - Partes tontas se unen para generar resultados } \\
\text { inteligentes. } \\
\text { - El liderazgo superior evita que lo inferior se atasque. } \\
\text { - Ampliar los límites de acción de las partes inferiores. }\end{array}$ \\
\hline $\begin{array}{l}\text { 2.- } \\
\text { Focalizar la } \\
\text { productividad e } \\
\text { incrementar el } \\
\text { Rendimiento. }\end{array}$ & $\begin{array}{l}\text { 1. Alcanzar el éxito generativo y auto-reforzante. } \\
\text { 2. Generar adicionalmente externalidades } \\
\text { positivas. } \\
\text { 3. Coordinar webs pequeñas. } \\
\text { 4. Desarrollar bucles de autocontrol. } \\
\text { 5. Emplear la Regla de Drucker: } 10 \text { veces mejor } \\
\text { que el anterior. } \\
\text { 6. Diseñar un juego de éxito para todos. }\end{array}$ & $\begin{array}{l}\text { - Mientras el número de clientes crece aritméticamente, el } \\
\text { valor de la red crece exponencialmente. } \\
\text { - Los que tienen más, reciben más. } \\
\text { - La red es una matriz tecnológica de comportamiento } \\
\text { biológico. } \\
\text { - Los sistemas tecnológicos tienen crecimiento biológico. } \\
\text { - La cultura es tecnológica. } \\
\text { - Las ganancias tiene efecto compuesto. }\end{array}$ \\
\hline
\end{tabular}




\begin{tabular}{|c|c|c|}
\hline $\begin{array}{l}\text { 3.- Crear la abundancia, } \\
\text { eliminar la escasez. }\end{array}$ & 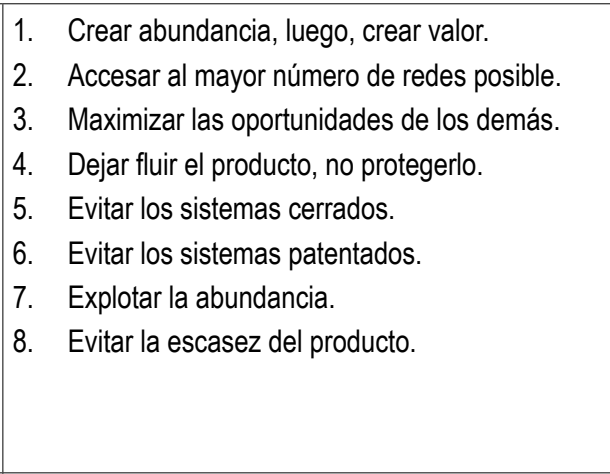 & $\begin{array}{l}\text { - Efecto fax. } \\
\text { - La abundancia de productos crea valor en la red. } \\
\text { - Cuando un sistema cerrado se abre y se interconecta, } \\
\text { todo el sistema adquiere mayor valor. } \\
\text { - El valor de un invento aumenta exponencialmente } \\
\text { mientras sus usuarios aumentan linealmente. } \\
\text { - A mayor interconexión, mayores oportunidades para su } \\
\text { empleo (bueno o malo). } \\
\text { - Ley de la abundancia: a más oportunidades } \\
\text { aprovechadas, surgirán mayores oportunidades nuevas. } \\
\text { - Una red siempre genera oportunidades. }\end{array}$ \\
\hline 4.- Perseguir el precio cero. & $\begin{array}{l}\text { 1. Ser generoso y ser recompensado por la red. } \\
\text { 2. Dar mejores productos, cada vez más baratos } \\
\text { 3. Identificar lo que se puede regalar. } \\
\text { 4. Invertir en el primer artículo. } \\
\text { 5. Prever el abaratamiento. } \\
\text { 6. } \\
\text { uso. } \\
\text { 7. Enfocar tarifa fija, no facturar por volumen de } \\
\text { mercado. } \\
\text { 8. } \\
\text { Regalar el producto principal, cobrar los } \\
\text { secundarios. }\end{array}$ & $\begin{array}{l}\text { - Los ciclos de retroalimentación contribuyen a la mejora. } \\
\text { - Los precios tienden a cero, y lo mejor es anticiparse. } \\
\text { - Todos los productos que se pueden copiar se abaratan a } \\
\text { - La tecnología crea demanda y luego la satisface. } \\
\text { - La expansión simultánea del conocimiento y la } \\
\text { tecnología aumenta la curva de demanda y disminuye la } \\
\text { curva de oferta. } \\
\text { - Inventar productos a velocidad superior a su } \\
\text { comercialización. } \\
\text { - Los productos más valiosos son los ubicuos y gratuitos. } \\
\text { - Regalar productos posiciona en la mente, lo que se } \\
\text { convierte en cuota de mercado. } \\
\text { - Lo única que escaseará es la atención humana. } \\
\text { - Estrategia del regalo en movimiento permanente: } \\
\text { ubicuidad y contribución. } \\
\text { - Lanzar productos beta para que los clientes lo } \\
\text { desarrollen. }\end{array}$ \\
\hline $\begin{array}{l}\text { 5.- Hacer crecer la web, al } \\
\text { principio. }\end{array}$ & $\begin{array}{l}\text { 1. Hacer progresar la red para hacer progresar a } \\
\text { 2. Mantener la red próspera y maximizar su valor. } \\
\text { 3. Buscar el máximo denominador común. } \\
\text { 4. No invertir en esperanto. } \\
\text { 5. Aplicar estándares instalados en nuevos } \\
\text { territorios. } \\
\text { 6. Iniciar el empleo de la red. } \\
\text { 7. Adoptar la red. } \\
\text { 8. Extender la web. }\end{array}$ & $\begin{array}{l}\text { - La primera cosa que la economía de red reforma es } \\
\text { nuestra identidad. } \\
\text { - La lealtad no está en las empresas, está en las redes y } \\
\text { las plataformas de red. } \\
\text { - El destino de la red y de la empresa van juntos. } \\
\text { - Crear alianzas a partir de las redes. } \\
\text { - El objetivo principal es la maximización del valor de la } \\
\text { red. } \\
\text { - Toda red tiene un ciclo de tres fases: pre estándar, } \\
\text { cambio, instauración. } \\
\text { - Para la máxima prosperidad se debe mantener la red } \\
\text { actualizada. } \\
\text { - A mayor intangibilidad de los productos, se precisa } \\
\text { - Enayor número de estándares. } \\
\text { - En el futuro, las normas técnicas serán tan importantes } \\
\text { como las leyes. } \\
\text { - Para prosperar, alimentar la red elevando el número de } \\
\text { - La ruarios. } \\
\text { - La lógica de la red abarcará todas nuestras } \\
\text { interacciones. } \\
\text { - Con el éxito de la información las empresas se } \\
\text { desplazan hacia la economía interconectada. }\end{array}$ \\
\hline
\end{tabular}


La economía y la sociedad del conocimiento.

Hacia la tercera revolución: la información

\begin{tabular}{|c|c|c|}
\hline $\begin{array}{l}\text { 6.- Llegar a la cúspide y } \\
\text { volver a empezar. }\end{array}$ & $\begin{array}{l}\text { 1. Renovar, después del éxito. } \\
\text { 2. No confundir claridad de visión con distancia de } \\
\text { previsión. } \\
\text { 3. Extender la red. } \\
\text { 4. Identificar quién está a cargo de la renovación. } \\
\text { 5. Cuestionar el éxito. } \\
\text { 6. Crear actitud vital: búsqueda incesante y } \\
\text { permanente como forma de vida. } \\
\text { 7. Identificar la cima correcta y definir la meta }\end{array}$ & $\begin{array}{l}\text { - Riesgo de quedarse estancado en una cima menor. } \\
\text { - Toda buena compañía tiende a subir. } \\
\text { - La competencia en innovación parte de la competencia } \\
\text { den demoler lo establecido. } \\
\text { - Abandonar la cima es un acto contra la ineficacia a largo } \\
\text { plazo. } \\
\text { - Es más fácil crear una organización nueva que cambiar } \\
\text { una organización antigua. } \\
\text { - Para maximizar la innovación maximice los márgenes. }\end{array}$ \\
\hline $\begin{array}{l}\text { 7.- Trabajar en espacios, } \\
\text { no en lugares. }\end{array}$ & $\begin{array}{l}\text { 1. Construir una clase diferente de grandeza } \\
\text { 2. Trascender: el límite de una red está fuera de } \\
\text { la red. } \\
\text { 3. Estar preparado para grandes volúmenes. } \\
\text { 4. Manejar la ola: el público se va desplazando } \\
\text { en ciclos. }\end{array}$ & $\begin{array}{l}\text { - Las personas habitan lugares, la economía habita en el } \\
\text { espacio. } \\
\text { - La economía de redes reemplaza lugares por espacios. } \\
\text { - En el ciberespacio, el valor fluye a través de webs. } \\
\text { - Donde existen redes existen intermediarios. } \\
\text { - Todos los puntos de una red son intermediarios. } \\
\text { - Lo mejor tendrá un tipo de grandeza diferente. } \\
\text { - Se incrementará la tecnología para la producción } \\
\text { personalizada. } \\
\text { - La comunidad precede al comercio. } \\
\text { - La red cambia los medios de masa por medios de } \\
\text { confusión. }\end{array}$ \\
\hline $\begin{array}{l}\text { 8.- Cambiar. La estabilidad } \\
\text { no existe, todo fluye, } \\
\text { todo se transforma. }\end{array}$ & $\begin{array}{l}\text { 1. } \text { Buscar el desequilibrio sostenible } \\
\text { 2. Caminar al filo del caos. } \\
\text { 3. Explotar el flujo, en lugar de rechazarlo. } \\
\text { 4. } \\
\text { Cultivar la complejidad. No implantar la } \\
\text { 5. } \\
\text { Complejidad. }\end{array}$ & $\begin{array}{l}\text { - En la economía de redes, el estado es dinámico, las } \\
\text { cosas no cambian, fluyen. } \\
\text { - Si el sistema alcanza el equilibrio y la armonía es porque } \\
\text { se está estancando y muriendo. } \\
\text { - El objetivo de la nueva economía es restablecer la } \\
\text { economía industrial. } \\
\text { - Para mantener la innovación hay que mantener el } \\
\text { desequilibrio. } \\
\text { - El cambio se produce en diferentes proporciones. }\end{array}$ \\
\hline $\begin{array}{l}\text { 9.- Adoptar la tecnología de } \\
\text { relaciones }\end{array}$ & $\begin{array}{l}\text { 1. Empezar con tecnología, culminar con } \\
\text { confianza. } \\
\text { 2. Adoptar la tecnología de relaciones, la que } \\
\text { sustenta la SIC. Sus clientes deben ser tan } \\
\text { inteligentes como usted. } \\
\text { 3. Conectar a todos los clientes entre sí. } \\
\text { 4. Elegir la tecnología que conecte, ante } \\
\text { condiciones iguales. } \\
\text { 5. Considerar a sus clientes como empleados. }\end{array}$ & $\begin{array}{l}\text { - El imperativo económico es la ampliación de relaciones. } \\
\text { - Cuando la información es abundante los homólogos } \\
\text { - Las nuev el control. } \\
\text { - de empleados y clientes, hasta formar una sola unidad. } \\
\text { - Prosumir es la fusión de producción y consumo. } \\
\text { - Crear lo que el cliente desea. } \\
\text { - Recordar lo que el cliente desea. } \\
\text { - La relación es entre dos partes. } \\
\text { - Anticiparse a los deseos del cliente } \\
\text { - Cambiar los deseos del cliente. } \\
\text { - El que tiene el cliente más listo es el que gana. } \\
\text { - Los clientes más fanáticos son los más expertos. } \\
\text { - La información se desplaza al cliente. } \\
\text { - Simetría del conocimiento. }\end{array}$ \\
\hline $\begin{array}{l}\text { 10.- Buscar las } \\
\text { oportunidades antes } \\
\text { que la eficiencia. }\end{array}$ & $\begin{array}{l}\text { 1. Buscar oportunidades, no solo resolver } \\
\text { problemas. } \\
\text { 2. Hacer que las máquinas realicen el trabajo } \\
\text { rutinario. } \\
\text { 3. Buscar las sorpresas positivas. } \\
\text { 4. Maximizar la cascada de oportunidades. }\end{array}$ & $\begin{array}{l}\text { - El origen de la riqueza económica está en las } \\
\text { oportunidades. } \\
\text { - No solucione problemas, aproveche las oportunidades. } \\
\text { - Se gana más generando nuevas oportunidades antes } \\
\text { que optimizando las oportunidades existentes. } \\
\text { - La productividad es aquello de lo que no hay que } \\
\text { preocuparse. } \\
\text { - Hacer lo adecuado es más provechoso que hacer lo } \\
\text { mismo un poco mejor. }\end{array}$ \\
\hline
\end{tabular}

Fuente: Elaboración propia. Adaptado de Kelly, New rules for the New Economy. 


\section{CONCLUSIONES SOBRE LA SIC}

La fase del desarrollo en que se encuentran los países, se caracteriza por el drástico cambio conceptual de la nueva economía, las fuentes de generación de valor, la gestión del conocimiento y el funcionamiento de las organizaciones.

La generación, acumulación y distribución del conocimiento muestra un crecimiento sin precedentes, sustentado en el avance tecnológico de las telecomunicaciones, las tecnologías de información y las redes complejas interconectadas. Este cambio acelerado afecta a todos los niveles de la vida en sociedad, modifica tendencias y reglas de mercado, renueva estrategias empresariales y redefine los modelos de creación de riqueza y generación de valor. La actividad humana se va reorientando, la acción propia se enfoca en el ocio improductivo, la acción social muestra la tendencia a reemplazar el contacto personal directo cara-a-cara por el contacto a través de medios electrónicos que falsean y distorsionan la realidad.

Se redefinen las cosmovisiones. Por un lado, la extensión espacial se torna accesible, cualquier lugar del mundo está cerca, se puede llegar o acceder a cualquier sitio, por otro lado, el concepto de tiempo secuencial se diluye y surge el concepto de momento donde el lapso de duración para ejecutar tareas tiende a cero, el acceso es instantáneo, sin demora y los cambios se aceleran y reproducen bajo modelos biológicos. Se agrega una nueva concepción de la realidad, no conocida ni descrita antes: la realidad virtual frente a la realidad concreta, el ciberespacio frente al espacio y las tareas on-line frente a las tareas por lotes o continuas.

Se presenta la paradoja del exceso de información, cada vez mayor, que no se puede asimilar, sistematizar ni controlar. La praxis se va concentrando en comunidades del saber, con nuevas élites y nuevos marginales: los generadores y poseedores del conocimiento verdadero controladores de los medios frente a los consumidores mediáticos receptores de información basura.

\section{En síntesis}

La sociedad de la información y el conocimiento, definida como la tercera revolución: de la información, ha generado cambios en los paradigmas y en la teoría económica.

La economía que aparece con la revolución de la información se basa en la tecnología digital, medios de transmisión, flujos crecientes de datos e infor- mación. Se estructura como una matriz de redes interconectadas, con nuevos comportamientos que la hacen diferente al funcionamiento de la economía de los sectores industriales tradicionales.

La SIC, como herramienta de desarrollo, ha de tener un rol primordial en la mejora de la competitividad de los países, lo que dependerá de los resultados empresariales y de la integración de los actores del sector con los actores de producción, servicios y normativos.

\section{REFERENCIAS BIBLIOGRÁFICAS}

Acevedo, A. (2003). Enfoque de los sistemas sociotécnicos en la Sociedad de la Información. Anales XVI Congreso Latinoamericano de Estrategia, las\&Slade. Perú.

Acevedo y Linares (2006). El desarrollo tecnológico de las telecomunicaciones: en el camino hacia la Sociedad de la Información. Revista AHCIET, №.107. España.

Adell Hernani \& Martínez-Albelda (2002). La construcción de la Sociedad de la Información en España. Perspectiva 2001-2005. Comunicaciones de Telefónica. № 24. España.

Aristóteles (1998). Ética a Nicómaco. Editorial ALBA, España.

Blair, R. \& Whitston, W. (1973). Elementos de Ingeniería de Sistemas Industriales. Editorial Prentice/ Hall Internacional.

Christensen, C. (1999). El dilema de los innovadores. Editorial Granica S.A., México.

Handy, Ch. (1997). Encontrar sentido en la incertidumbre, en Repensando el futuro. Editado por Rowan Gibson. Colombia.

Kelly, K. (1999). New rules for the New Economy. Penguin Books, USA.

Kelly, K. (1997). La nueva biología de los negocios, en Repensando el futuro. Editado por Rowan Gibson. Colombia.

Le Monde Diplomatique (2002). El mito Internet. Editorial Aún creemos en los sueños. Chile.

Linares, C. (2010). El reto regulatorio en el contexto de la Sociedad de la Información y el Conocimiento. Paper. 
Magretta, J. (2001). La administración en la nueva economía. Editorial Oxford University Press México S.A. de C.V.

Nonaka y Takeuchi (1999). La organización creadora de conocimiento: Cómo las compañías japonesas crean la dinámica de la innovación. Editorial Oxford University Press México.

Parkin, M. (1995). Microeconomía. Addison Wesley, USA.
Pazos, Rodríguez, Rodríguez-Patón, Suárez (2007). Gestión del conocimiento. Paraninfo. España.

Quintás, G. (2002). Términos y usos del lenguaje filosófico. Universitat de Valencia, España.

Seybold y Marshak (2000). Clientes.com. Cómo crear un estrategia de negocios rentable para la Internet y el futuro. Editorial Granica S.A. Argentina.

Tapscott, D. (2000). La creación de valor en la economía digital. Editorial Granica S.A. Argentina. 